\title{
The connection of hydronephrosis and microcirculation deterioration
}

\author{
DMYtro Vorobets
}

Department of Urology, Danylo Halytsky Lviv National Medical University, 69 Pekarska, 79010 Lviv, Ukraine

\begin{tabular}{|c|c|}
\hline ARTICLE INFO & ABSTRACT \\
\hline $\begin{array}{l}\text { Received } 07 \text { March } 2016 \\
\text { Accepted } 01 \text { April } 2016\end{array}$ & \multirow{2}{*}{$\begin{array}{l}\text { In this study, we have analyzed the influence of hydronephrosis upon the microcirculation } \\
\text { system, in situations of pyeloureteral junction obstruction. Herein, bulbar conjunctiva } \\
\text { has been chosen as the object of this biomicroscopic study because of its simplicity } \\
\text { and the method availability in clinic practice. In fulfilling this work, we ascertained the } \\
\text { connections between extravascular, intravascular, vascular and general conjunctival } \\
\text { indices of the patients before radical and paliatic correction of the pyeloureteral junction } \\
\text { obstruction (i.e. by open and laparoscopic pyeloplasty, endopyelotomy, laser resection } \\
\text { and balloon dilatation). We concluded that, apart from the proved deterioration of kidney } \\
\text { function, systemic deteriorations of microcirculation may be observed in situations of } \\
\text { clinically marked hydronephrosis, according to the results of radioisotope renography } \\
\text { and excretory urography. }\end{array}$} \\
\hline $\begin{array}{l}\text { Keywords: } \\
\text { pyeloureteral junction } \\
\text { obstruction, }\end{array}$ & \\
\hline
\end{tabular}

\section{INTRODUCTION}

With regard to the kidney parenchyma and pyeloureteral segments, because of hydronephrosis pathogenesis, as well as morphogenesis, a radical ablation of displasive tissues is the only pathogenetically substantiated treatment for obstruction. The influence of the method upon the haemostasis and fibrinolysis systems which actively react to pathological changes in the urinary system (especially during surgical intervention), is due to the engendered hydronephrotic transformation. This brings about increased hemorrhage during operations and the danger of post-operative intravascular thrombosis [1].

The complexity and variety of this pathogenesis promotes the appearance of many prognostic criteria, the understanding of which gives the possibility to ascertain the influence of laparoscopic pyeloplasty upon the haemostasis system [2, $5,6]$. In our study, a profound analysis of literature data was first carried out, and we drew the conclusion that biomicroscopic research is a rather effective method for diagnosing the microcirculation condition [7]. Moreover, we held that the bulbar conjunctiva is the best perspective for clinical research. This is due to the absence of essential peculiarities of anatomy character. It is also so because of the chaotic location of vessels (hence, the bulbar conjunctiva can be considered as being a suitable morphological substrate for

\footnotetext{
* Corresponding author

e-mail:dv@ukr.net
}

a hemorrhage that is not connected with the specific functions of a particular organ), as well as the good contrast of its erythrocytes against a white sclera background. Finally, it is also because of the presence of a natural irrigational system (a lachrymal apparatus), hence, minimizing the usual microscopy heat effect upon the vessels [8].

The aim of our research was to compare with the indices of clinically healthy persons, the indices of bulbar microscopy of patients with hydronephrosis before different surgical interventions.

\section{MATERIAL AND METHODS}

Patients with pyeloureteral junction stricture were grouped depending on the carried out type of treatment: for 46 patients - open pyeloplasty according to Hynes-Anderson procedures, for 46 patients - laparoscopic pyeloplast; for 26 patients - endopyeloplasty, for 17 patients - balloon dilatation; for 13 patients - laser resection. The individual groups were also combined into one super endourological methodics group, with the addition of 56 people for more significant certainty during statistical analysis. For the study, the bulbar conjunctival biomicroscopy technique was used for assessment [3].

The following pathological occurrences of conjunctival microcirculation are well-described and well-systematized: the deterioration in the arteriolovenular ratio of diameters, the presence of a spidery structure, micro-aneurisms, as 
well as sackings (sack-like varicose veins), the creation of vascular bundles, evidence of hemorrhaging and the creation of intravascular erythrocytes aggregates [4].

In our work, an extravascular component was estimated according to the presence of hemorrhages and perivascular oedema. These induce a dullness of background. Moreover, the engendered intravascular erythrocytes aggregation is a distinctly marked morphological phenomenon resembling broken regions of vascular contour divided by light stripes of plasma. This phenomenon is made unequal due to its expressiveness, reversibility and location within different regions of microvascular net.

\section{RESULTS AND DISCUSSION}

The conjunctival indices of patients with hydronephrosis of the second or third degree (and who had been directed to surgical intervention), actually did not differ from that of patients with clinically indistinct hydronephrosis of the first degree $(p>0,05)$ (table 1). However, the tendency to worse indices testifies to systemic vascular pathology in the patients with hydronephrosis, and which exhibit greater than average values of extravascular conjunctival index $\left(\mathrm{CI}_{1}\right)(\mathrm{p}=0,082)$, and of vascular conjunctival index $\left(\mathrm{CI}_{2}\right)(\mathrm{p}=0,066)$, as well as of general conjunctival index $\left(\mathrm{CI}_{\text {gen }}\right)(\mathrm{p}=0,075)$. In this work, the validity of T-test has been demonstrated during the calculations of T-value, which for $\mathrm{CI}_{1}, \mathrm{CI}_{3}, \mathrm{CI}_{\mathrm{gen}}$ approached 1.96. In addition, dispersions of samples by the indices of extravascular, intravascular, vascular and general conjunctival indices did not essentially differ.

Table 1. Indices of conjunctival index (CI) in open pyeloplasty patients, in comparison with the indices of a control $(\mathrm{n} 1=46$; $\mathrm{n} 2=19$ )

\begin{tabular}{|c|c|c|c|c|}
\hline CI & 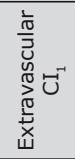 & 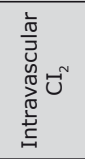 & 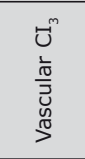 & $\frac{\sqrt{\bar{\sigma}}}{U^{-}}$ \\
\hline Average Value, $\bar{x}$ & 1 & 4,848 & 11,848 & 17,696 \\
\hline Standard Deviation, S & 0,422 & 0,868 & 1,534 & 2,393 \\
\hline $\begin{array}{l}\text { Standard Deviation of the } \\
\text { Mean, } \mathrm{S}^{\bar{x}}\end{array}$ & 0,062 & 0,128 & 0,226 & 0,353 \\
\hline Variance & 0,178 & 0,754 & 2,354 & 5,728 \\
\hline F-criterion & 0,724 & 1,743 & 0,828 & 0,914 \\
\hline F-test (Sig.) & 0,375 & 0,201 & 0,592 & 0,777 \\
\hline Diff. Average Values, $\bar{X}_{2}-\bar{X}_{1}$ & 0,368 & $-0,257$ & 2,058 & 2,169 \\
\hline T-test (Sig.) & 0,082 & 0,200 & 0,066 & 0,075 \\
\hline T-value & 1,743 & 1,301 & 1,894 & 1,819 \\
\hline
\end{tabular}

In 38 of 46 patients examined before laparoscopic pyeloplasty intervention, with regard to their vascular pathology (as seen via conjunctival bulbar microscopy), a greater extravascular conjunctival index value was observed, when compared to that of clinically healthy persons. Herein, the difference of average values was $0.368(p=0.005)$. These patients also displayed a greater vascular conjunctival index value. In this regard, the difference of average values between these and that of healthy persons was $2.1(\mathrm{p}=0.052)$. Still, the comparative dispersions of samples according to the indices $\mathrm{CI}_{2}, \mathrm{CI}_{3}$ and $\mathrm{CI}_{\text {gen }}$ did not cardinally differ. The obtained data directly reveals a higher probability of systemic vascular deterioration in patients that, due to hydronephrosis, had one ill-functioning kidney (Table 2).

Table 2. Indices of conjunctival index in patients to whom laparoscopic pyeloplasty was proposed, in comparison with the indices of patients of the control group $(\mathrm{n} 1=38 ; \mathrm{n} 2=19)$

\begin{tabular}{|c|c|c|c|c|}
\hline CI & 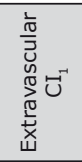 & 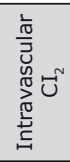 & 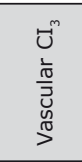 & 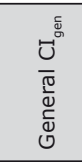 \\
\hline Average Value, $\bar{x}$ & 1 & 5,263 & 11,895 & 17,895 \\
\hline Standard Deviation, S & 0 & 0,795 & 1,247 & 2,215 \\
\hline $\begin{array}{l}\text { Standard Deviation of the } \\
\text { Mean, } S^{x}\end{array}$ & 0 & 0,129 & 0,202 & 0,359 \\
\hline Variance & 0 & 0,632 & 1,556 & 4,908 \\
\hline F-criterion & 0 & 1,459 & 0,548 & 0,784 \\
\hline F-test (Sig.) & N/A & 0,394 & 0,120 & 0,516 \\
\hline Diff. Average Values, $\bar{X}_{2}-\bar{X}_{1}$ & 0,368 & 0,158 & 2,105 & 2,368 \\
\hline T-test (Sig.) & 0,005 & 0,431 & 0,052 & 0,086 \\
\hline T-value & 3,240 & 0,795 & 2,023 & 1,497 \\
\hline
\end{tabular}

Actual differences in the values of all CI, when compared to that of the control group, were not observed in regard to the conjunctival index of patients of a heterogeneous group $(n=46)$ that is with both pyeloureteral junction obstructions and hydronephrosis, and to whom paliatic interventions were proposed (either via laser resection, endopyelotomy or balloon dilatation). The data dispersion of such values was also tight and homogenous. Hence, we put forward that a systemic vascular pathology (which could have affected the indices of conjunctival bulbar microscopy), was not observed in these patients (Table 3).

Table 3. Indices of conjunctival index in patients to whom endopyelotomy was proposed, in comparison with the indices of the patients of the control $(\mathrm{n} 1=46 ; \mathrm{n} 2=19)$

\begin{tabular}{|c|c|c|c|c|}
\hline CI & 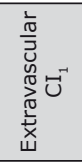 & 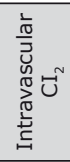 & $\begin{array}{l}\underbrace{m} \\
\frac{1}{0} \\
\frac{0}{3} \\
\stackrel{y}{0} \\
3\end{array}$ & 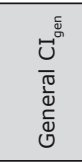 \\
\hline Average Value, $\bar{X}$ & 0,761 & 5,283 & 9,935 & 15,957 \\
\hline Standard Deviation, S & 0,431 & 0,720 & 2,070 & 2,867 \\
\hline $\begin{array}{l}\text { Standard Deviation of the } \\
\text { Mean, } \mathrm{S}^{\mathrm{x}}\end{array}$ & 0,064 & 0,106 & 0,305 & 0,423 \\
\hline Variance & 0,186 & 0,518 & 4,285 & 8,220 \\
\hline F-criterion & 0,757 & 1,198 & 1,508 & 1,312 \\
\hline F-test (Sig.) & 0,442 & 0,696 & 0,346 & 0,540 \\
\hline Diff. Average Values, $\bar{X}_{2}-\bar{X}_{1}$ & 0,129 & 0,177 & 0,145 & 0,430 \\
\hline T-test (Sig.) & 0,329 & 0,343 & 0,770 & 0,550 \\
\hline T-value & 0,992 & 0,961 & 0,295 & 0,603 \\
\hline
\end{tabular}

What is more, by all indices of conjunctival analysis, the laparoscopic pyeloplasty group did not essentially differ from the open pyeloplasty group (Table 4). 
Table 4. Conjunctival index indices of patients to whom laparoscopic pyeloplasty was proposed, in comparison with that of patients to whom open pyeloplasty was recommended $(\mathrm{n} 1=38$, $\mathrm{n} 2=46)$

\begin{tabular}{|c|c|c|c|c|}
\hline CI & 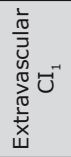 & 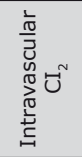 & 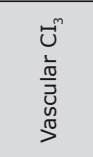 & 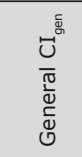 \\
\hline Average Value, $\bar{X}$ & 1 & 5,263 & 11,895 & 17,895 \\
\hline Standard Deviation, S & 0 & 0,795 & 1,247 & 2,215 \\
\hline $\begin{array}{l}\text { Standard Deviation of the } \\
\text { Mean, } S^{\bar{x}}\end{array}$ & 0 & 0,129 & 0,202 & 0,359 \\
\hline Variance & 0 & 0,632 & 1,556 & 4,908 \\
\hline F-criterion & 0 & 0,838 & 0,661 & 0,857 \\
\hline F-test (Sig.) & N/A & 0,583 & 0,198 & 0,633 \\
\hline Diff. Average Values, $\bar{X}_{2}-\bar{X}_{1}$ & 0 & 0,415 & 0,047 & 0,199 \\
\hline T-test (Sig.) & 1 & 0,025 & 0,878 & 0,694 \\
\hline T-value & 0 & 2,286 & 0,155 & 0,395 \\
\hline
\end{tabular}

The obtained conjunctival indices data of those treated by way of laparoscopic pyeloplasty, did not practically differ from the data of patients who had undergone open pyeloplasty according to Anderson-Hynes. Herein, the intravascular CI2 value was worse (greater by 0.415$)(\mathrm{p}=0.025)$ in the laparoscopic pyeloplasty group. Thus, on average, they actually had a worse vascular status than did the open pyeloplasty group (evidenced by way of T-value calculations).

It should be noted that, with regard to vascular, extravascular and intravascular conjunctival index values, dispersions of the endoscopic group and the open operations group did not considerably differ (Table 5).

Table 5. Indices of conjunctival index in endopyelotomy patients, in comparison with that of open pyeloplasty patients $(n 1=46$; $\mathrm{n} 2=46)$

\begin{tabular}{|c|c|c|c|c|}
\hline $\mathrm{CI}$ & 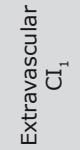 & 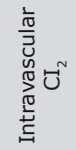 & $\begin{array}{l}U^{m} \\
\frac{1}{0} \\
\frac{\pi}{3} \\
0 \\
0 \\
0\end{array}$ & $\frac{\overbrace{}^{\frac{\Xi}{\sigma}}}{\frac{0}{0}}$ \\
\hline Average Value, $\bar{X}$ & 0,761 & 5,283 & 9,935 & 15,957 \\
\hline Standard Deviation, S & 0,431 & 0,720 & 2,070 & 2,867 \\
\hline $\begin{array}{l}\text { Standard Deviation of the } \\
\text { Mean, } \mathrm{S}^{\bar{x}}\end{array}$ & 0,064 & 0,106 & 0,305 & 0,423 \\
\hline Variance & 0,186 & 0,518 & 4,285 & 8,220 \\
\hline F-criterion & 1,046 & 0,687 & 1,820 & 1,435 \\
\hline F-test (Sig.) & 0,880 & 0,212 & 0,047 & 0,229 \\
\hline Diff. Average Values, $\bar{X}_{2}-\bar{X}_{1}$ & $-0,239$ & 0,435 & $-1,913$ & $-1,739$ \\
\hline T-test (Sig.) & 0,129 & 0,021 & 0,09 & 0,07 \\
\hline T-value & 1,689 & 2,614 & 1,836 & 1,758 \\
\hline
\end{tabular}

As to the vascular pathology of pyeloureteral junction obstruction (observed during conjunctival bulbar microscopy) in patients of balloon dilatation, endopyelotomy and laser resection, when compared to open pyeloplasty patients, $\mathrm{CI} 3$ and CIgen indices are lower - indicating better vascular status. Herein, the difference of average values are -1.913 and -1.739 ( $\mathrm{p}=0.09$ and 0.07 ). Of this obtained data, only a lower average CI2 value in the endopyelotomy patients $(p=0.021)$ appeared to be of note.

\section{CONCLUSION}

Systematic microcirculation deterioration may be observed in situations of intensive hydronephrosis when examined by way of radioisotopic renography and excretory urography.

\section{REFERENCES}

1. Alyev M. M. et. al. Otdalennye rezul'taty plastyky pyeloureteral'nogo segmenta v zavisimosty ot ob'ema rezekcyy lohanky. Pedyatryja, $1,91,2002$.

2. de Broe M. et al. Clinical nephrotoxins: renal injury from drugs and chemicals. Springer Science and Business Media, 481, 2013.

3. Konstantinov O.G. et al. Russian patent "Device for conjunctival microcopies"; TOI DVO RAN; Bull. N 31, Appl.10.01.2006.; publ. 10.11.2006.

4. Konstantinova E.E., Tsapaeva N.L. Conjunctival biomicroscopy method which uses a device with a video camera HC-I for slit lamps in the assessment of microcirculation in cardiovascular disease. Cardiology, 13, 2002.

5. Krosovskaya T.V. et al. Diagnostic criteria for functional and organic lesion UPJ in infants. Pediatric Surgery, 2, 17, 2002.

6. Lam P.W. et al. Pediatric laparoscopic pyeloplasty: 4-year experience. J. of Endourology, 21, 12, 2007.

7. Mikheev I.G. et al. Method of conjunctival biomicroscopy using a new generation of video cameras in the assessment of microcirculation in children and adolescents with developmental abnormalities of the urinary system. Pediatria, 6, 26, 2010.

8. Volosok N.I. et al. Conjunctivas' biomicroscopy in the assessment of microcirculation in glomerulonephritis in children. Nephrology and Dialysis, 1, 47, 1999. 